$\mathbb{T}$ periodica polytechnica

Architecture

$38 / 2(2007) 61-65$

doi: 10.3311/pp.ar.2007-2.03

web: http://www.pp.bme.hu/ar

(c) Periodica Polytechnica 2007

RESEARCH ARTICLE

\section{A broad consideration of values - the opportunity for a designable future}

Bálint Orosz

Received 2006-10-11

\begin{abstract}
In accordance with international declarations, VÁTI applied new methods and instruments in the investigation and protection of community values and in the defining of their characteristics. These new methods were introduced through the example of a Hungarian city, Debrecen. The survey, identifying the characteristics of the city (character analysis), was completed in 2000.

VÁTI attached about 300 photographs, which were taken with the help of modern computing instruments for the character analysis, to a digital map. A 50-year-old photographic document of the city has also been attached to the same map, and all of these are documented on a $C D$, together with chapters on "value" protection both cultural and architectural.

Thus the present state of the city can be juxtaposed with that some 50 years ago, creating an invaluable document for the next generation.

Along with the value surveys, VÁTI also participated in the introduction of a modern building registration system. The technical information system is based on the use of data sheets for individual surveys of each of the buildings. The Swiss method of "RECENSEMENT" has been adapted and tested in Debrecen as "Deb-RECENSEMENT".
\end{abstract}

\section{Keywords}

protection $\cdot$ heritage $\cdot$ future

\section{Bálint Orosz}

VÁTI Urban Planning Ltd., 1075 Budapest, Madách tér 3-4., Hungary
The Grenade Agreement on the protection of the European Architectural Heritage - which has been in effect in Hungary since 1990 - turns the task of protecting our architectural heritage into an elementary task of regional and urban planning.

The most important statement of the International Charter for the Protection of Historic Cities, adopted at the Washington General Assembly of ICOMOS in 1987, is the fact that it handles the whole of the historic settlement as a unified historic monument.

Since that time, additional aspects have been developed and included in relation to the protection of our built heritage, and these justified the convocation of the Krakow 2000 Conference. The following is some of its conclusions with regard to historic settlements:

1 The historic city is an organic unit, and its values (that facilitate life) that deserve protection are linked with its inhabitants and the creations that are serving them.

2 The protection of the built heritage - taking into consideration the above statement, is significantly more than just "classic monument protection" that concentrates only on individual buildings of outstanding value and their immediate environment. The new approach requires new and different methods. Amongst these new methods, the widespread enumeration of values and their local protection is of significant importance. It is the task of the resident community together with the crucial participation of local government and involving the widest possible range of the local society.

3 Along with the protection of material constituents, the protection of the intangible, spiritual elements and the "genius loci" is similarly important in a historic city.

With reference to these points, it is intended to outline those new aspects, methods and instruments that have been applied by VÁTI in the City of Debrecen, East Hungary, in the fields of community value research, protection and the conservation of settlement characteristics.

The working material titled "Historical environment, development of the city, cityscape features and protection of values" has been elaborated for the city-planning of Debrecen in 1998. 
It comprises the following chapters:

\section{Settlement history}

2 Changes in regional role

3 The most characteristic features of the society in the city

4 Development of the city

5 Changes in the physical dimensions of the city

6 Cityscape features

7 Monument protection

8 Local protection of values

No basic research has been carried out for the preparation of the inspection material, it was based on the ample source material that was available.

The inspections of the physical dimensions of the city, the first (1782-85), the second (1829-66) and the third (1872-84) military maps of Debrecen served as a basis, whereas the analysis of the consecutive maps appearing in a 30-year period on average (1910-1936-1967-1998) has been completed by computer.

As a result of the inspection and as its most important achievement, we might state that the area of Debrecen - originating from four villages in the 12-13th centuries and circumvallated later on to form a 2-kilometre diameter circle - has increased twenty-fold from the 1740 s to present times, whereas the number of inhabitants has not grown accordingly.

This tendency is still tangible, since unjustified building activity on the outskirts of the city continues, whereas claims occurring - regarding e.g. the inner city which is waiting for rehabilitation - would be easily satisfied by the utilisation of the actual intra-area. This situation is further aggravated by the fact that the greatest loss from this expansion is the so-called Nagyerdő (Great Forest), north of the city. A 3-kilometre wide belt has already been sacrificed for the extensive growth.

The stormy history of the city - resulting partly from its location, the wars as well as fires occurring every 2-3 years until the beginning of the 19th Century, the accelerated development from that time and the new border-location following World War I, all played important roles in the evolvement of the present structure and building stock. The latter period also brought some advantages, the city became a university centre, which is illustrated by the fact that buildings of the medical university are in the process of gaining protected buildings status. However, the war and accommodating of refugees created their own problems and damage, the signs of which are still visible.

The bombings in WW II as well as poorly considered architectural interference with the traditional city structure in the 1970s are also tangible in the changed city structure and building stock.

The characteristic analysis - which is perhaps the most important inspection from a value protection perspective, has been completed in the preparation phase of the urban structure plan (master plan) in 2000. This analysis served as a basis for the "Programme for the protection of the cultural-historical and architectural heritage". Results of the characteristic analysis are illustrated on a 1:100.000 scale outline character-map, which facilitated an overview of characteristic buildings serving as a basis for the forthcoming regulation and protection.

In the case of Debrecen, the character analysis identified the following basic characteristic areas:

1 Inner city character
(a) City Centre
(b) "Civis" (civic) city 1

2 “Taksás” site2

3 Villa district

4 University district

5 Blocks of flats

6 Suburban
(a) Traditional Suburban
(b) New Suburban

7 “Kertségi" 3
(a) Western "kertségi"
(b) Trans-rail "kertségi"

8 “Külsőségi”"4

As it can be seen from this classification, names of specific features have an important accent in the arsenal of protection and in the capture of the "genius loci". Using the well-known local names of the individual settlement areas with their unique values is the best way to identify an individual physical-spiritual environment through the memories of inhabitants, and this solution is perhaps the simplest method of reaching the widest possible range of the local society.

Those typical characteristics of the built heritage that must be conserved for the future are thus rooted into the collective memory of the settlement, alongside the impersonal memory of the computer.

As a continuation of the work, analogically with the cityscape and the monument survey of Debrecen the 1950's - part of a national survey which covered 78 cities in Hungary, VÁTI completed a digital map with about 300 available photographs that were taken using up-to-date computing methods for the character analysis. This map enables quick and easy retrieval of the individual sites and their distinctive characteristics.

\footnotetext{
${ }^{1}$ The name "civis" means those (not too many) citizens who had civil professions but also were involved with agriculture and had the vote.

2 The name "taksás" refers to certain sites that were given to villains who had to pay an annual fee for site. This amount was called "taksa".

3 "Kertségi" refers to an area that was previously a vineyard system.

${ }^{4}$ The name "Külsőség" refers to the outskirts of the city and the surrounding settlements
} 


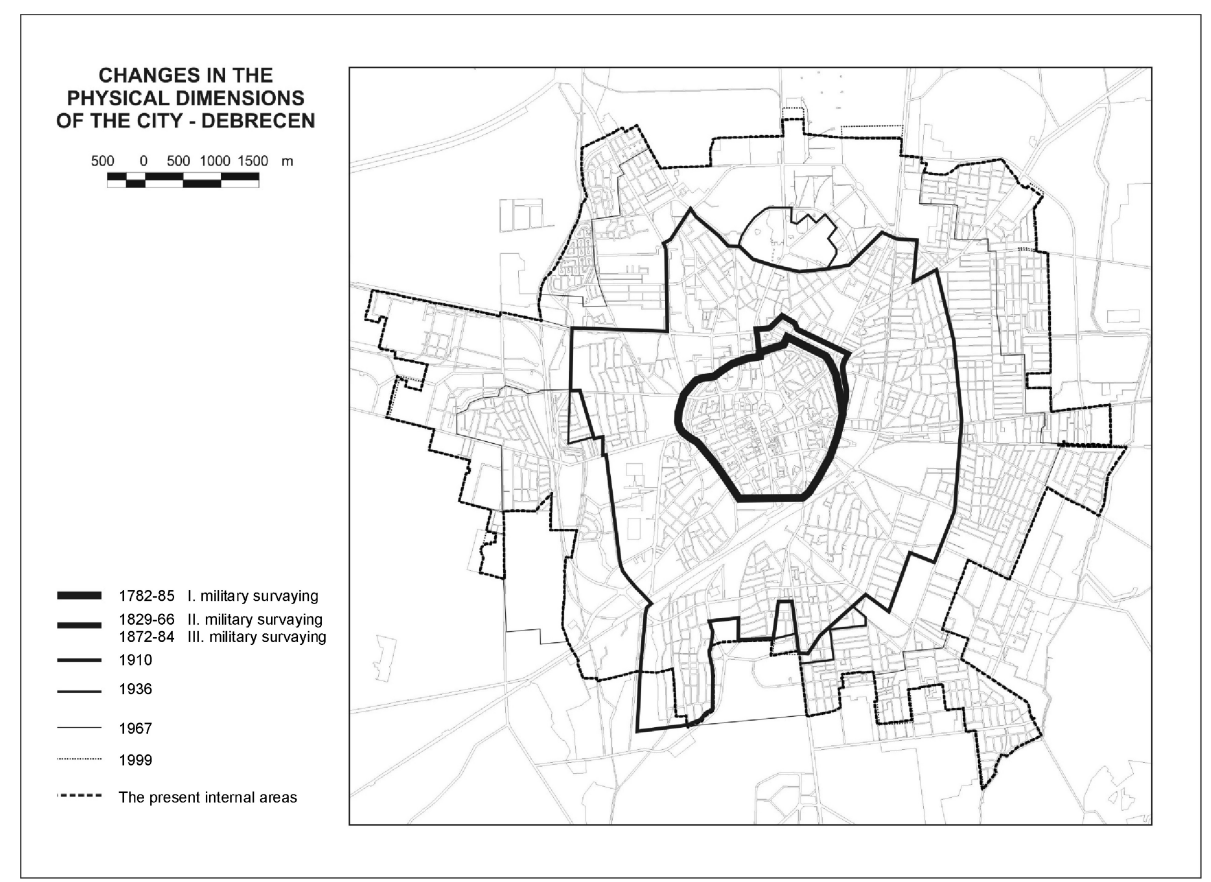

Fig. 1. Changes in the physical dimensions of the city - Debrecen

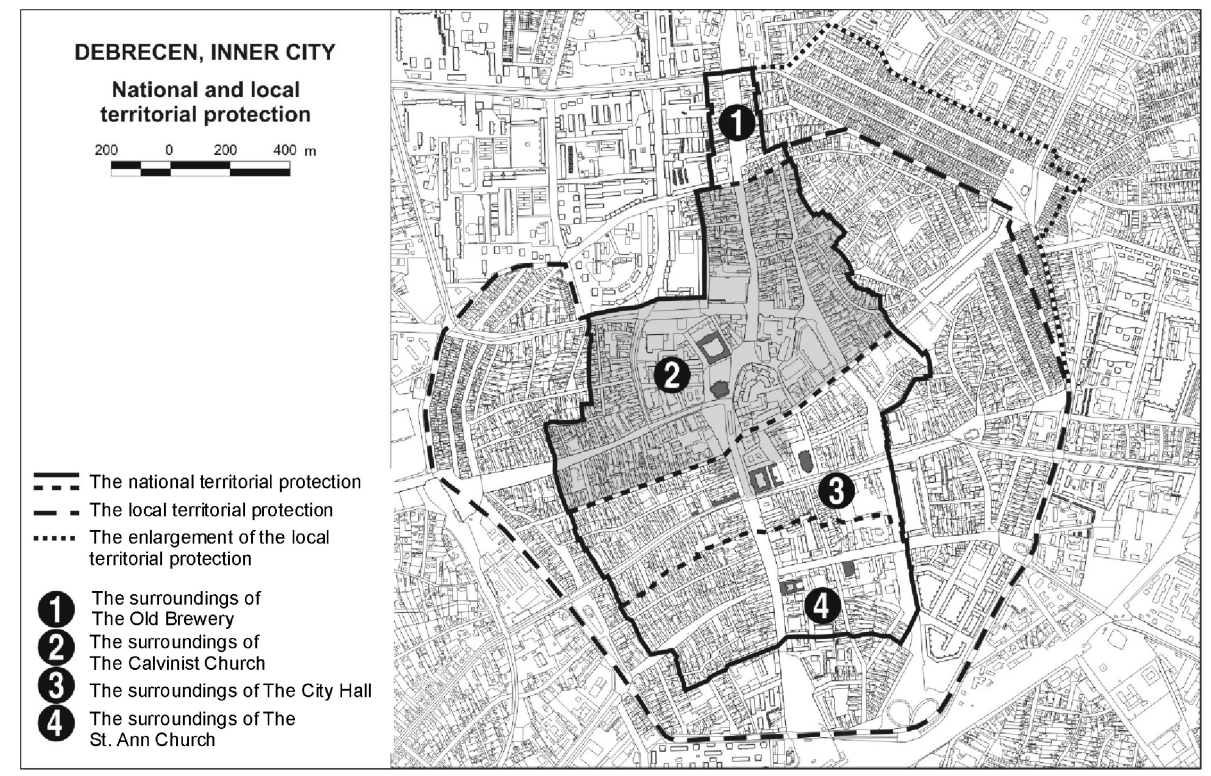

Fig. 2. Debrecen, inner city - National and local protection

It is interesting to note that the same map contains also 93 photographs taken in 1951 for the "Cityscape and monument analysis of Debrecen". These photos can all be easily accessed on the computer and enable such comparative analyses that must have an important role in the decision-making procedure concerning rehabilitation and cityscape planning, as well as individual architectural decisions in the future.

The computer-processed CD, which consists of the value protection chapters, cityscape analysis preceding the definition of characters, is an introduction of a method and at the same time an easy to use valuable document recording the present state of the city along with that of the 1950s for the following generations.

A few more words on the protection of the architectural heritage of the city:
In Debrecen, the program registers a relatively large number of locally protected buildings for national monument protection, contains the draft of the value protection regulation, and the digital map that facilitates an easy overview of the present and planned protection level of the built heritage in the city.

Along with protection, the program also contains the possibility for the introduction of a modern building-registry system, as the classification of the buildings has been carried out in Debrecen as an experiment, along with the preparation of the masterplan and with the cooperation of our office, in accordance with Swiss methods geared and adapted to Hungarian circumstances.

The Swiss technical information system, called RECENSEMENT based on the individual inspection of buildings, has been attached to the character analysis.

This value-classification method was first introduced to Hun- 
garian experts in November 1998 at a work conference organized by the Hungarian National Committee of ICOMOS, within the framework of a presentation by Swiss experts, where Debrecen was the first test of the method in Hungary.

The essence of the method is that a printed form helps with the analysis of the buildings. Filling in starts with land-registry data, which necessitates the examination of land-office registration data, since authentic data can only be retrieved from these sources. The following step is local data recording: inspection of the exterior of buildings, photographic documentation and classification of peculiar features with the aid of icons placed on the pre-printed digital form. This facilitates computerized data processing and unique value designation.

Buildings are classified into seven categories. The first category comprises buildings of national importance. The second category is related to buildings that require further research for their national level protection. Buildings worthy of measures for value protection steps, form the third category (translated to Hungarian circumstances, this is approximately equal to the level of local protection). The fourth category consists of buildings well fitting their environment. The fifth contains those encumbered with some problem, whereas valueless buildings form the sixth category. Those requiring unconditional intervention belong to category seven.

Following value estimation, results of the survey are presented to the owners through a slideshow. The local government is also represented at this presentation and copies of data sheets are handed to the owners. Registration of a building in Switzerland is based on these categories and those falling in the first three categories will be inserted in the federal (national) register, in accordance with the Swiss public administration. After confirmation, the protection is officially published and the owners are informed in a resolution. Protection lays certain charges on the owners, although they have an opportunity to gain financial assistance for the rehabilitation and due maintenance of their buildings.

The system provides further assurance, since demolition of buildings belonging to the first four categories is prohibited.

In the district of Vaud (Switzerland) approximately 70,000 buildings have been analysed during the past 20 years, and their data sheets are now accessible. $70 \%$ of the survey costs has been paid by the Swiss state and the local governments have provided 30 per cent.

According to their experience, completion required 1.9 hours on average and salaries added up to 10 per cent of the total registration costs. Provision of the professional supervision required one and a half man hours.

For Debrecen, the city only had to provide accommodation and offices for two Swiss colleagues for two six months periods, in exchange for valuable analysis data on 678 buildings in the most valuable area of the city, which is the richest in architectural values and deserves protection. (See Fig. 2)

The Hungarian translation of the data sheets and the support- ing documentation necessary for their completion has been prepared in the first phase in 1999. As a practical application of the method - with the aid of these data sheets - in 1999, about 100 buildings were analysed and documented within the environment of the Calvinist Great Church.

Buildings were classified into seven categories accordingly. After adaptation, the categories - adjusted to the Hungarian circumstances - were as follows:

Category 1:Nationally protected, historic buildings

Category 2:Locally protected, worthy of national protection

Category 3:Locally protected

Category 4:Buildings well fitting their environment or worthy of local protection

Category 5:Having certain qualities, though not excellent

Category 6:Uninteresting

Category 7:Not fitting into their environment

As a continuation of the work, the total analysis of the environment was accomplished in 2000. The map-processing of classified buildings gives an outline of the historic environment of the Church and shows strategic areas for intervention, serving as a thorough assistance for tasks concerning rehabilitation.

To enable rapid access, the computerized processing of data sheets - containing digital photographs - has also been done; these can be attached to the digital map.

VÁTI - also from its own resources - is presently working on the development of the method, aiming at the facilitation of computerized data sheet completion at the locations (using laptops) and of data retrieval by icons on the data sheets.

This development does not essentially change the structure of the data sheet; the first series of data remains to be administrative data as outlined above. Then the value estimation follows together with a list of planned measures, and finally, the type of the building including its present function and condition.

Among the features of a building, the most important is the orientation of the elevation, but the method of building and the number of floors are also recorded. Then the architectural characteristics: by pressing a certain button on the "data sheet", the computer records the type of the roof, the material of the roof, information on the roof windows, it "describes" the appearance of the façade, the type of ornamentations, the shape of doors and windows, their ornamentation and framework. Digital photographs of the building can be attached to the data sheet and individual features can also be recorded within this digital form.

In accordance with the international declarations concerning historic settlements, our aim is to develop a new instrument that is capable of a widespread inclusion of values and - within Hungarian circumstances - of the total data recording of historic buildings and total building stock in their environment, as well as of the processing of the evolving data base, founding a new practice in our country. This might well provide a new market opportunity for VÁTI.

Computerized administration - in case of consistent data 
recording - with the facility of data retrieval through categories or icons opens up new perspectives in the field of value protection.

The method under elaboration, which has been adapted to Hungarian circumstances, may be of interest for the National Monument Office as well as for the local governments.

Experiences of the Debrecen testing are utilised in the further development of the data sheet.

The opinion of the Swiss colleagues is worthy of consideration. Their general impression is that documentation in Hungary witnessed by them has been very precise and well archived, but these documents are not connected to a working structure.

It is enough to refer to the above mentioned cityscape and historic surveys from the 1950 s, which preserve irreproducible information on 78 Hungarian cities in some plan archives and records, on the state of the buildings almost 50 years ago, after the war and before the socialist recovery work. This issue is almost forgotten and unavailable nowadays.

It is also to be mentioned that the western countries - like Switzerland - that work consciously in the past 15-20 years on those methods that are by now essential to any actions concerning renovations, have already elaborated such software solutions that are capable of analysing financial possibilities to be used in the individual renovations.

They perceived well in advance those presently seen processes that lead to the increase in value of the built heritage and their large-scale renovation.

According to Swiss data, more than half of the building-trade consists of renovation and maintenance work. They have developed the so-called EPIQR method, which - apart from the aesthetic renovation of buildings - targets the energy-consumption of the building, the processing of resulting waste, also keeping in mind the need for increasing the comfort of inhabitants in the flats under renovation. In the first phase, all possible fragments of data are collected, which enables a diagnosis of the general condition of the building. Then the scale of necessary work is analysed and financial effects of the planned interventions are juxtaposed.

It is an important aspect that after the renovation, energy consumption of the building should be as minimal as possible, whereas interior comfort of the flats must be the highest possible.

Finally, let me add some thoughts about the main heading of the conference: Integrated Conservation.

The brief overview of the introduction shows a process that is tangible through the change of the concepts of architectural heritage, overall and holistic interpretation of the built environment, local protection of settlement segments that consist of after all everyday buildings, the improvement of the connection of the settlement and the landscape.

The value of such a broadly interpreted heritage is further increased if buildings that are traditionally taken as monuments are also present in the architectural environment.
This process might have been triggered by the appearance of residential areas in the 60's and 70's, which might seem to be spiritless with its uniform features, causing an increase in efforts for the protection of the local environment as a counter-reaction.

Thus the architectural heritage has gradually turned into a part of the cultural heritage with the "European Charter of Architectural Heritage" introducing the concept of integrated conservation in 1975, and the previously mentioned "Grenade Agreement" complementing it with the definition of various forms of the architectural heritage.

The new approach - with the need of the widest possible involvement of the local population - facilitated the appearance of more general, overall value protection conceptions. A stricter connection has been founded between culture and environment, drawing attention to the principle of sustainable development, compelling us to balance conservation and the rate of new building.

Therefore, integrated conservation is a combination of renovation and rehabilitation. Its aim is the general improvement of the quality of life, the development of the local economy, employment and private investments. These are accompanied by social flat building programmes, the conservation of the values of the built environment, preparation for the reception of new functions and the appearance of new economical, social and cultural values.

Integrated protection deserves systematic planning and the consideration of the cultural and economical capabilities in the actual building stock. This facilitates the conservation and reinforcement of the actual social, economic and cultural infrastructure. The trust of investors can be gained through active planning policy, strong political commitment and common participation.

Integrated protection is in that way - contrary to those interpretations referring to the protection of all elements of our environment - a form of conservation integrated into development, which requires the adoption and application of those new methods and instruments that are introduced through the example of Debrecen, and which have become undeniable needs in the region in the present day.

\section{References}

1 Harrach $\mathbf{E}$, A helyi védelmet elókészítő munkák Svájcban, Múemlékvédelem (1999), no. 2.

2 Orosz B, Módszertani bemutató és szakmai véleménycsere,Debrecen, December 14 1999, 2000.

3 _ Térinformatika a települési karakterkutatásban, 2000. 